\section{Laser Visualization of Bullet Paths}

\author{
Vecellio $\mathbf{M}^{*}$ and Hooper $\mathbf{S}$ \\ Department of Justice Studies-Applied Forensic Science, Methodist University, \\ USA
}

\begin{abstract}
Investigators routinely utilize lasers to visualize bullet paths during the reconstruction of shooting incidents. Visualizing the approximate bullet path with a laser is an important technique that can help identify positions of shooters and victims and locate key items of physical evidence. Following a review of conventional methods, the authors present a simple technique: The application of water mist with a standard spray bottle. This technique is inexpensive, and yields results similar to conventional methods.
\end{abstract}

\section{Introduction}

Crime scene investigators, analysts, and reconstructionists frequently use lasers to visualize bullet paths during the reconstruction of shooting incidents. Establishing and visualizing the bullet path is a critically important technique that can provide investigators with a wealth of information regarding shooter and victim positions and aid in identification and recovery of evidence, such as cartridge cases and projectiles [1-5]. Photographing the laser-visualized bullet path requires specialized techniques. Following a review of common methods, the author introduces a simple and inexpensive technique.

A common manner of determining the bullet's estimated trajectory is through use of trajectory rods [1-5]. Researchers have shown, that though trajectory rods donot provide the actual parabolic pathway of a bullet, the straight-line representation of the trajectory rodis accurate and reliable over a short distance [6,7]. Investigators obtain and record vertical and azimuth (horizontal) angles to document the angle at which the bullet impacted the surface. Extending this bullet path from the trajectory rod into space is a crucial step that allows investigators to visualize the straight line representation of the bullet path.

*Corresponding author: Vecellio M, Department of Justice Studies-Applied Forensic Science, Assistant Professor, Methodist University, USA, Tel: +1 9106307000; E-mail: mvecellio@methodist.edu

Citation: Vecellio M, Hooper S (2020) Laser Visualization of Bullet Paths. Forensic Leg Investig Sci 6: 049.

Received: July 13, 2020; Accepted: July 27, 2020; Published: August 03, 2020

Copyright: ( 2020 Vecellio M, et al. This is an open-access article distributed under the terms of the Creative Commons Attribution License, which permits unrestricted use, distribution, and reproduction in any medium, provided the original author and source are credited.
Investigators may use string for this purpose, but generally prefer lasers because of their ease of use and effectiveness in displaying a straight line. Commercial suppliers often equip trajectory rod kits with rods that allow the attachment of lasers to the end of the rods. Lasers, however, are generally not visible through space and require specialized photographic techniques to capture the laser beam and surrounding scene $[1-5,8]$.

\section{Commonly Employed Methods of Visualizing Lasers}

Two conventional methods are frequently used to visualize and photograph the laser-indicatedbullet path [1-4]. Neither method is complex, but both require the investigator to possess competence with advanced camera functions and settings.

The card method requires that an investigator hold a piece of cardboard at a 45-degree angle in relation to the camera, while ensuring the laser beam strikes the card. The investigatorwalks along the laser beam while holding the card in a manner that allows the beam to remain in contact with the card. To photographically capture the laser, while avoiding capturing the investigator holding the card, this process must occur in low light or through use of neutral density filters as described by Lemasters, et al. [9]. After the investigator walks the entire length of the laser beam in darkness, the photographer can add fill light to the digital image (Figure 1). This method is relatively uncomplicated and creates an intense laser beam image. The primary disadvantage is that obstructions may prevent an investigator from walking along the entire pathway of the laser. In these instances, one must employ an alternative method.

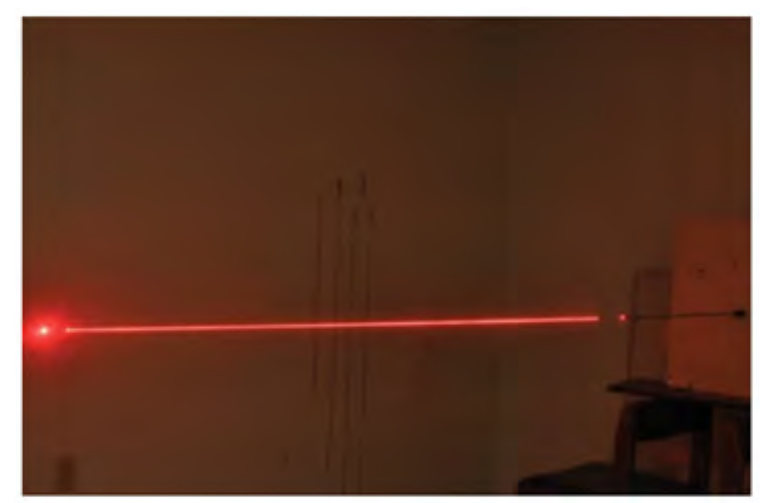

Figure 1: The author used the card image to visualize the laser path in this image. Fill-flash with a flashlight was used to provide lighting. Shutter Speed: 13s. Aperture: f/4.5. ISO: 400 .

A second commonly employed method involves the use of commercially available smoke sprays. Investigators spray smoke onto the laser beam, which allows visualization of the laser. This must occur in darkness to ensure the investigator spraying the laser beam is not visible in the image. Fog machines can be used in an analogous manner, when practical. Investigators can add light to the image to visualize 
the surroundings using fill light (Figure 2). This method is simple to employ, and investigators can use it when obstacles limit the ability to walk along the bullet path, as required for the card method. Possible disadvantages of this method are the introduction of chemicals into the crime scene along with the cost of the smoke-spray formulas, at least in comparison with the proposed novel method: using water mist.

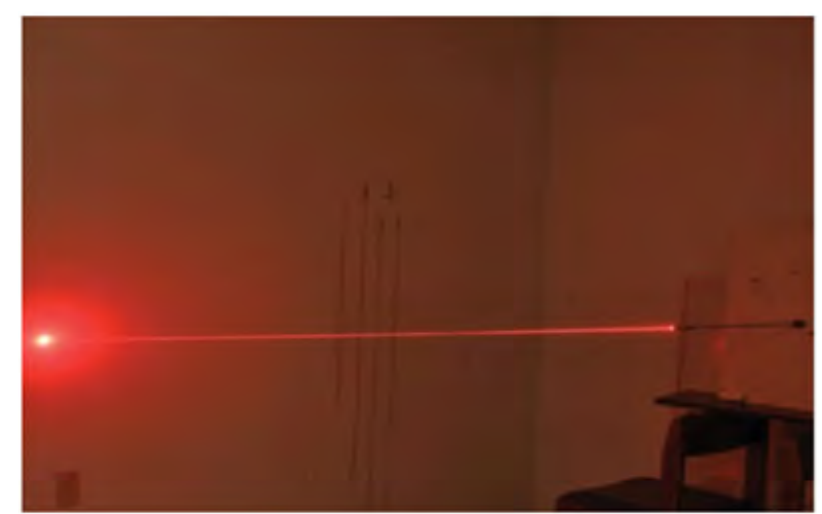

Figure 2: The author used the smoke-spray method to visualize the laser path in this image. Fill-flash with a flashlight was used fill flash to provide lighting. Shutter speed: 13 s. Aperture: f/4.5. ISO: 400 .

The novel water-mist method (Figure 3), not previously described in literature, resembles the smoke-spray technique, but with the use of water in a spray bottle capable of generating a fine mist.Atomizers are particularly effective. The investigator will spray water onto the laser beam in darkness. This technique yields comparable results as smoke and, of course, is inexpensive and does not introduce chemicals to the scene. The intensity of the laser visibility is somewhat diminished, in comparison with smoke spray, so conducting this technique in a dark environment is critical. The author has successfully tested tap water from a wide range of locations.

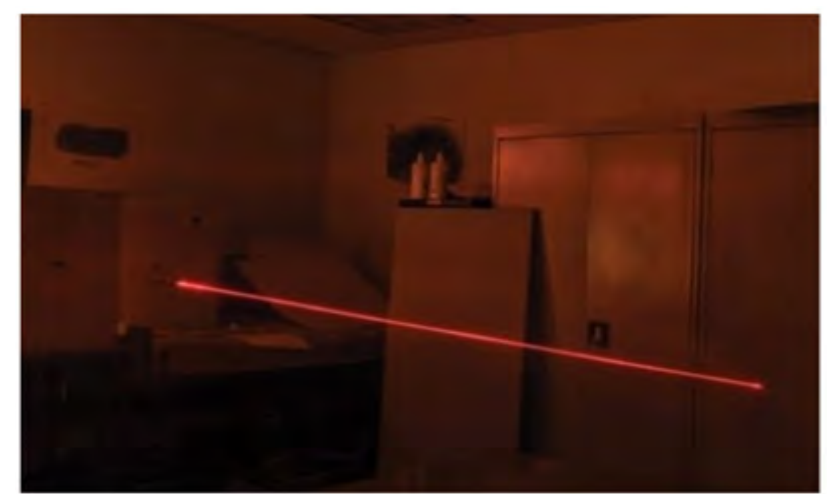

Figure 3: The author used the water-mist method to visualize the laser path in this image. Fill flash with a flashlight was used to provide lighting. Exposure time: 13s. Aperture: f/4.5. ISO: 400 .

The distribution of water as a fine-mist spray shares similar properties with other aerosols, such as smoke spray. The aerosol water droplets created with a spray have relatively small radii (only a few microns), and thus have a slow fall velocity. This allows the fine water mist to linger in the air for an appreciable amount of time, enabling its use for effective laser beam visualization.

\section{Photography Tips}

Investigators must follow some common photographic principles whether using smoke, water, or the card method. A slow shutter speed is essential to capturing the laser beam. A tripod is also essential to prevent blur from handheld camera shake. Photographers will have some latitude with the f-stop, though lower number f-stops (wider apertures) allow more light into the image. The downside, however, is a loss of depth of field: the range of the image from foreground to background that appears in sharp focus. The investigator should consider using higher number f-stops in crime scenes with objects at various distances, to ensure everything is in focus. If the photographer uses a higher number f-stop, he or she must adjust the shutter speed or ISO to allow more light in the image. The ISO choice will be dependent upon the shutter speed and f-stop selections, along with the camera's ISO technology. Higher ISOs can create lower quality images that appear noisy. However, since advances in technology over the past few years have reduced this risk, the photographer should consider taking test images with the camera to determine a suitable upper limit for the ISO.

Because investigators photograph lasers in low light to allow visualization of the laser, the addition of fill light allows imaging of the scene along with the laser beam. A photographer can add fill light by using a flashlight, camera flash or other source of light. The photographer must be careful to not add too much light, which will prevent the laser beam from being visible in the image. Practicing this technique is highly recommended.

\section{Review of Methods}

\section{Card method}

- Set the camera on a tripod and focus the lens. Select an appropriate f-stop, shutter speed, and ISO depending on light conditions and depth-of-field preferences. Be aware that too much ambient light creates a "ghosting" effect, which photographically captures the investigator walking with the card.Since one must perform this technique in dark or low light conditions, one may also choose to use the "bulb" shutter speed.

- One investigator walks along the laser beam, holding the card at a 45-degree angle towards the camera, ensuring the laser beam strikes the card. The investigator may choose to create a dotted laser line by removing the card from the laser beam for specified intervals while walking along the laser beam. The investigator should walk at a pace of about one foot per second to avoid the "ghosting "effect.

- With the shutter still open, add fill light after the investigator completes the process of capturing the laser beam and exits the image area.

\section{Smoke-spray and water-misting methods}

- Set the camera on a tripod and focus the lens. Select the appropriate f-stop, shutter speed, and ISOdepending on light conditions and depth-of-field requirements. Be aware that too much ambient light may create the "ghosting" effect. Since one must perform this 
technique in dark or low light conditions, one may also choose to use the "bulb" shutter speed.

- An investigator will spray the smoke or water at the laser beam. If using water, select a spray bottle that generates a fine mist.An atomizer is particularly effective. Spray enough smoke or water to ensure clear visualization of the laser beam.

- After the investigator applies smoke or water to visualize the laser, with the shutter still open, the photographer will add fillflash, being careful to ensure the investigator spraying the smoke or water is out of the image.

\section{Conclusion}

Visualization and photography of laser-enhanced bullet paths is an essential component of shooting incident reconstructions. Conventional methods of visualizing and photographing lasers include the card method and the smoke-spray method. The authors present asimple, convenientmethod using fine-mist water spray. This method yields results comparable to conventional methods and is inexpensive.

\section{References}

1. ATF-LS-FT16 Procedural Guideline Shooting Trajectory Analysis (2018) Bureau of Alcohol, Tobacco, Firearms and Explosives.
2. Chisum W, Turvey B (2011) Shooting Incident Reconstruction Part I. Crime Reconstruction, 2nd Ed, Elsevier: Maarssen, Netherlands, Pg no: 365-421.

3. Haag M, Haag L (2011) Shooting incident reconstruction, $2^{\text {nd }} E d$, Academic Press: San Diego, Pg no: 175-188.

4. Hueske E (2015) Shooting Reconstruction Equipment and its use. Practical Analysis and Reconstruction of Shooting Incidents, $2^{\text {nd }}$ Ed, Taylor \& Francis: Abingdon, United Kingdom, Pg no: 99-123.

5. Projectile Path Reconstruction Essential Elements Guideline (2012) Scientific Working Group for Firearms and Toolmarks (SWGGUN).

6. M Haag (2008) The accuracy and precision of trajectory measurement. AFTE 40: 145-182.

7. Mattijssen E Kerkhoff W (2016) Bullet trajectory reconstruction-Methods, accuracy and precision. Forensic Science International 262: 204-211.

8. Courtney M, Hueske E (1994) Theuse of hand-held laser pointers in the reconstruction of events at a crime scene-A technical note. AFTE 26: 170172.

9. Lemasters T, Johnson D, Miller B (2018) Laser bullet trajectory photography. J Forensic Identif 68: 223-233. 


\section{di}

Advances In Industrial Biotechnology | ISSN: 2639-5665

Advances In Microbiology Research | ISSN: 2689-694X

Archives Of Surgery And Surgical Education | ISSN: 2689-3126

Archives Of Urology

Archives Of Zoological Studies | ISSN: 2640-7779

Current Trends Medical And Biological Engineering

International Journal Of Case Reports And Therapeutic Studies | ISSN: 2689-310X

Journal Of Addiction \& Addictive Disorders | ISSN: 2578-7276

Journal Of Agronomy \& Agricultural Science | ISSN: 2689-8292

Journal Of AIDS Clinical Research \& STDs | ISSN: 2572-7370

Journal Of Alcoholism Drug Abuse \& Substance Dependence | ISSN: 2572-9594

Journal Of Allergy Disorders \& Therapy | ISSN: 2470-749X

Journal Of Alternative Complementary \& Integrative Medicine | ISSN: 2470-7562

Journal Of Alzheimers \& Neurodegenerative Diseases | ISSN: 2572-9608

Journal Of Anesthesia \& Clinical Care | ISSN: 2378-8879

Journal Of Angiology \& Vascular Surgery | ISSN: 2572-7397

Journal Of Animal Research \& Veterinary Science | ISSN: 2639-3751

Journal Of Aquaculture \& Fisheries | ISSN: 2576-5523

Journal Of Atmospheric \& Earth Sciences | ISSN: 2689-8780

Journal Of Biotech Research \& Biochemistry

Journal Of Brain \& Neuroscience Research

Journal Of Cancer Biology \& Treatment | ISSN: 2470-7546

Journal Of Cardiology Study \& Research | ISSN: 2640-768X

Journal Of Cell Biology \& Cell Metabolism | ISSN: 2381-1943

Journal Of Clinical Dermatology \& Therapy | ISSN: 2378-8771

Journal Of Clinical Immunology \& Immunotherapy | ISSN: 2378-8844

Journal Of Clinical Studies \& Medical Case Reports | ISSN: 2378-8801

Journal Of Community Medicine \& Public Health Care | ISSN: 2381-1978

Journal Of Cytology \& Tissue Biology | ISSN: 2378-9107

Journal Of Dairy Research \& Technology | ISSN: 2688-9315

Journal Of Dentistry Oral Health \& Cosmesis | ISSN: 2473-6783

Journal Of Diabetes \& Metabolic Disorders | ISSN: 2381-201X

Journal Of Emergency Medicine Trauma \& Surgical Care | ISSN: 2378-8798

Journal Of Environmental Science Current Research | ISSN: 2643-5020

Journal Of Food Science \& Nutrition | ISSN: 2470-1076

Journal Of Forensic Legal \& Investigative Sciences | ISSN: 2473-733X

Journal Of Gastroenterology \& Hepatology Research | ISSN: 2574-2566
Journal Of Genetics \& Genomic Sciences | ISSN: 2574-2485

Journal Of Gerontology \& Geriatric Medicine | ISSN: 2381-8662

Journal Of Hematology Blood Transfusion \& Disorders | ISSN: 2572-2999

Journal Of Hospice \& Palliative Medical Care

Journal Of Human Endocrinology | ISSN: 2572-9640

Journal Of Infectious \& Non Infectious Diseases | ISSN: 2381-8654

Journal Of Internal Medicine \& Primary Healthcare | ISSN: 2574-2493

Journal Of Light \& Laser Current Trends

Journal Of Medicine Study \& Research | ISSN: 2639-5657

Journal Of Modern Chemical Sciences

Journal Of Nanotechnology Nanomedicine \& Nanobiotechnology | ISSN: 2381-2044 Journal Of Neonatology \& Clinical Pediatrics | ISSN: 2378-878X

Journal Of Nephrology \& Renal Therapy | ISSN: 2473-7313

Journal Of Non Invasive Vascular Investigation | ISSN: 2572-7400

Journal Of Nuclear Medicine Radiology \& Radiation Therapy | ISSN: 2572-7419

Journal Of Obesity \& Weight Loss | ISSN: 2473-7372

Journal Of Ophthalmology \& Clinical Research | ISSN: 2378-8887

Journal Of Orthopedic Research \& Physiotherapy | ISSN: 2381-2052

Journal Of Otolaryngology Head \& Neck Surgery | ISSN: 2573-010X

Journal Of Pathology Clinical \& Medical Research

Journal Of Pharmacology Pharmaceutics \& Pharmacovigilance | ISSN: 2639-5649

Journal Of Physical Medicine Rehabilitation \& Disabilities | ISSN: 2381-8670

Journal Of Plant Science Current Research | ISSN: 2639-3743

Journal Of Practical \& Professional Nursing | ISSN: 2639-5681

Journal Of Protein Research \& Bioinformatics

Journal Of Psychiatry Depression \& Anxiety | ISSN: 2573-0150

Journal Of Pulmonary Medicine \& Respiratory Research | ISSN: 2573-0177

Journal Of Reproductive Medicine Gynaecology \& Obstetrics | ISSN: 2574-2574

Journal Of Stem Cells Research Development \& Therapy | ISSN: 2381-2060

Journal Of Surgery Current Trends \& Innovations | ISSN: 2578-7284

Journal Of Toxicology Current Research | ISSN: 2639-3735

Journal Of Translational Science And Research

Journal Of Vaccines Research \& Vaccination | ISSN: 2573-0193

Journal Of Virology \& Antivirals

Sports Medicine And Injury Care Journal | ISSN: 2689-8829

Trends In Anatomy \& Physiology | ISSN: 2640-7752

Submit Your Manuscript: https://www.heraldopenaccess.us/submit-manuscript 